\title{
Preparing for a Global Society: Lessons from Successful Education Systems across the World
}

\author{
Anya Niazov, Ed.D. \\ DePaul University \\ Chicago, IL, USA
}

\begin{abstract}
The world is becoming an increasingly interconnected marketplace not only for goods and services but also for education and ideas. This paper focuses on U.S. students' preparation for a global society through an exploration of the literature regarding international academic achievement. It first explores the notion that U.S. academic achievement is not successful by international standards. Then, by analyzing testing data from the Program for International Student Assessment (P.I.S.A.) and the Third International Mathematics and Science Study (T.I.M.S.S.) it reveals a number of countries including Canada, Finland, Singapore and Japan that have produced high levels of achievement when compared to the U.S. Going beyond the tests, it then looks at how these countries have organized their educational systems to be successful and specifically examines their utilization of educational resources, attempts to achieve educational equity, and improve teacher quality. Cultural differences and the challenges of implementing successful international strategies in America are expressed. Based on the literature, it is apparent that there are multiple ways to achieve academic success in the educational world and that given this multiplicity of successes, our struggling education system has a variety of strategies it can employ to regain a position of international preeminence.
\end{abstract}

Keywords: international comparative education, international tests, teacher training, cultural differences, United States, Japan, Singapore, Canada, Finland, PISA, TIMSS.

\section{Are United States students being prepared for a global society? Lessons learned from successful K-12 education systems across the world.}

"If we just had more accountability, if we just had better teachers, if the teachers just cared more about children, if we just paid them more, if we could just operate schools under free-market principles, if we could just operate them more democratically, if 
we just put a computer on every desk, if we could just get schools to make decisions based on data, if we could just make lifelong learners of teachers, if we just put teachers in professional learning communities, if we just guaranteed every child a college education, everything would be all right." (Payne M. C, 2010, p. 45-46)

The if we just and what if statements Payne (2010) lists represent deficiencies that exist in every educational system in the United States and overseas. These statements and nations' lack of actions to achieve them are often the cause of educational failures. However, in other parts of the globe these same statements, and actions to achieve the ifs, are the causes of educational success.

This work focuses on the evidence to support education reform learned from other countries, improving the educational system in the United States, explores the successful strategies as they exist overseas, and lastly poses the challenges and possible ways to overcome existing barriers.

\section{Importance of the topic}

The globe is becoming increasingly small and fluid economically; workers from all countries either are or will soon be competing not only with those from their own localities, but internationally (Organization for Economic Co-operation and Development (O.E.C.D.), 2010). Given this new economic reality, jobs will go to the most educated students from around the world (Paine \& Schleicher, 2011, p. 2). Education and international educational competitiveness is becoming increasingly important (Tucker, 2011). In order to build a competitive global educational system, there is a need to work together and learn from the experiences of other countries (Tsuneyoshi, 2001, p.190).

For American students, global competition is an increasingly challenging insecure prospect (Partnership for $21^{\text {st }}$ Century Skills, 2009). In the landmark $A$ Nation at Risk report, the American education system was heavily criticized for its uninspiring performance in preparing students academically to compete internationally (The National Commission on Excellence in Education, 1983). With the advent of international tests like Program for International Student Assessment (P.I.S.A.) and Third International Mathematics and Science Study (T.I.M.S.S.), U.S. performance has been shown to lag behind that of other countries.

\section{The terms "successful" and "effective" in the international context}

The terms "successful education" and "effective schools" appear frequently, however, are frequently poorly defined. A large number of authors use relative international test scores to infer educational success. The two most frequently cited sources of the data for international comparisons are the Third International Mathematics and Science Study (T.I.M.S.S.) and Program for International Student Assessment (P.I.S.A.). Tucker (2011) tries to expand the definition of success by including not only high average academic achievement based on international tests, but also educational equity and cost effectiveness. While these types of analysis are intriguing, according to Hofman, Hofman \& 
Gray (2010) although international tests are valuable in comparing countries with similar socio-economic circumstances, their usefulness is questionable when conducting broad international comparisons, therefore to identify successful nations in the literature, this paper will use "successful" and "effective" terms to reflect countries who score favorably on international tests.

\section{International Tests}

TIMSS Methodology.

The Trends in International Mathematics and Science Study (TIMSS) a program from the International Association for the Evaluation of Education, measures math and science skills amongst students in $4^{\text {th }}$ and $8^{\text {th }}$ grade from roughly 50 countries. According to the writers of the TIMSS test, its goals are to "monitor system-level achievement trends in a global context", "establish achievement goals and standards for educational improvement", to "stimulate curriculum reform", and to "improve teaching and learning through research and analysis of the data" (TIMSS and PIRLS International Study Center, 2013). It uses short, fact-oriented stems and primarily multiple-choice questions. The TIMSS test is based on curricular and proficiency benchmarks and focuses on the three cognitive domains of knowing, applying, and reasoning to determine "how well students have mastered the factual and procedural knowledge taught in school mathematics and science curricula" (Kell \& Kell, 2010). The test has been administered in 1995, 1999, 2003, 2007, and 2011. While sampling is not uniform worldwide, in the U.S., a probability sample is drawn for each test nationally, and includes 480 schools with almost 19,000 students in 2003 (Kell \& Kell, 2010).

\section{PISA Methodology.}

PISA, the Programme for International Student Assessment, is a test designed by the Organization for Economic Cooperation and Development (OECD) that tests 15 year-olds from across the globe in the areas of reading, mathematics, and science. Every three years since 2000, over 65 countries that have participated in these assessments which use open-ended questions that look at real-life applications (OECD, 2007). The test specifically attempts to determine how students can extrapolate their knowledge with higher order reasoning and analysis to apply their knowledge to novel situations (Schleicher, 2009; Kell \& Kell, 2010). Around 470,000 representative students were selected to participate in the 2009 test, representing about $18 \%$ of 26 million eligible 15 year olds from the 65 participating countries (OECD, 2011).

\section{TIMSS Results In Brief.}

The 1995 TIMSS test showed that U.S. fourth-graders were not elite in the domains of mathematics and science, with students scoring only slightly above the international average in both of these areas (Baker \& LeTendre, 2005). Similarly, U.S. eighth-graders performed "near the international average in both mathematics and science", while the U.S. twelfth-graders scored "below the international average and among the lowest of the TIMSS nations in mathematics and science general knowledge, as well as in physics and advanced mathematics" (Gonzales et al., 2008). On repeat testing in 2011, U.S. 4th and 8th 
grade students performed slightly better than previously and above average in both mathematics and science. East Asian nations were the countries scoring highest on the 2011 TIMSS test including Singapore, Korea, Hong Kong, Taipei, and Japan (TIMSS and PIRLS International Study Center, 2012).

\section{PISA Results In Brief.}

On the 2006 PISA science assessment, the United States ranked 21st among 30 OECD countries, with a confidence interval that extends from the 18th to the 25th rank (OECD, 2007). Moreover, while the proportion of top performers in the United States was similar to the OECD average, "the United States had a comparatively large proportion of poor performers: $24.4 \%$ of United States 15-year-olds did not reach Level 2, the baseline level of achievement on the PISA scale at which students begin to demonstrate the science competencies that will enable them to participate actively in life situations related to science and technology" (Schleicher, 2009). Given this high rate of low achievement and the large population of the U.S. compared to other nations, the United States produces the most low-achieving students of any of the 34 nations tested (Petrilli \& Scull, 2011). PISA's 2009 test showed that U.S. 15 year olds performed around the average in reading (rank 14), and science (rank 17) and below the average in mathematics (rank 25) among 34 participating countries while Korea and Finland were among the top 3 scoring nations in each of these content areas (OECD, 2011). Similarly, the 2012 PISA test demonstrates that students from the United States again performed below OECD average in mathematics, and near the OECD average in reading and science while nations such as China (Shanghai), Japan, Finland, Singapore, and Canada each were each above average (in the top twelve out of sixty-five participating countries) in all three testing categories (OECD, 2013). One caveat about interpretation of US results is that they were not uniform; while some states like Massachusetts performed near the top of OECD countries, other states (like Mississippi and California) performed very poorly. In the most recent iteration of PISA, U.S. students' reading and science scores held steady, but mathematics performance again dropped, this time to $31^{\text {st }}$ of 72 participating nations (Barshay, 2016).

\section{Lessons to Learn from International Tests}

The results of PISA and TIMSS have widely been used as a means to identify top-scoring nations and then to subsequently study them further and learn lessons from their successes. A great deal of scholarship has gone into learning about the education in Finland, Singapore, Korea, and other top scoring nations. Beyond simply analyzing the scores of these nations, scholars have also focused on nations' equity and achievement between rich and poor students. Baker \& LeTendre (2005) note that TIMSS data show that U.S. students from disadvantaged backgrounds are much more likely to fail in school than similarly disadvantaged students in other countries. However, as Darling-Hammond (2011) notes, despite the fact that "disparities have come to appear inevitable in the United States...they are not the norm in developed nations around the world, which fund their education systems centrally and equally, with additional resources often going to the schools where students' needs are greater" (p.21). 
Darling-Hammond (2011) makes the case that the top scoring nations have structured reforms to focus on learning goals, accountability systems, fair resource distribution, professional standards and supports for teachers. According to Cavanagh (2012), high-scoring countries tend to recruit and retain talented teachers and help them continually improve their classroom skills. Furthermore, they combine clear, ambitious academic standards for all students with a strong degree of autonomy at the local school level which enables researchers and policymakers to "go pretty far in understanding what makes education systems succeed ... and derive a lot of lessons from them" (p.4).

\section{Criticisms of International Tests}

While there is little debate that nations are becoming more interconnected economically, educational scholars frequently disagree about whether students from countries with different cultural and economic circumstances can or should be compared in terms of academic success due to inherent differences (Schleicher, 2009). Given this fundamental concern, the entire concept of international testing has been called into question and there have been indictments of PISA and TIMSS on the basis of issues of misinterpretation of data, narrow focus, and issues of generalizability (Bracey, 2009; Boe \& Shin, 2005; Kell \& Kell, 2010; Berliner \& Biddle, 1996; Ravitch, 2013). Considering that the results of the tests indicate that U.S. students have lower scores on international tests compared to high-achieving nations, scholars who do not see the U.S. educational system as lagging behind other nations have been critical of the data from these tests and argue that they are not useful to U.S. students because they divert attention from more important and pressing issues like lack of resources (Baker, 2007).

International tests can be seen from a variety of lenses; as Boe and Shin (2005) note, it is a matter of interpretation:

“One can pick a particular survey (e.g., TIMSS 1995), subject matter (e.g., mathematics), and grade level (e.g., grade 8) and find "many" industrialized nations that scored significantly higher than the U.S. (e.g., France, Japan, and Switzerland). Yet it is also true that U.S. students perform better than students in many industrialized nations. For example, the U.S. scored significantly higher than many industrialized nations (e.g., France, Germany, and Switzerland) in the 1991 Reading Literacy Study at grade 4. Thus, depending on one's interest or agenda, a particular survey result can be selected to support almost any conclusion about how the U.S. stands in the international achievement horse race" (p. 194).

Methodologic and statistical issues are also worth noting. Rutkowski \& Rutkowski (2016) note methodological limitations including sampling problems (poor reporting of exclusion rates and misalignment between PISA's sampling goals and population coverage), the achievement estimation model used by the tests, and inconsistent documentation of trend data across countries and test implementations. 
Furthermore, Boe \& Shin argue that much of the perception of disappointing U.S. test results is related to math and that this ignores U.S. performance in other subjects. Zhao (2007) similarly argues that these tests focus too much on rote recall in math and science at the expense of creativity and critical thinking. He argues that if nations focus too much on these tests scores, such a focus can extinguish students' creativity by leading to a teaching to the test mentality instead of one focused on cultivation of students' learning and passion. Furthermore, other scholars argue that the primary data from PISA and TIMSS are misinterpreted because the tests only measure discrete knowledge and do not assess the quality of nations' educational systems as a whole (Rotberg, 2006). Another issue Boe and Shin (2005) describe is that the way these scores are reported: the U.S. average performance is often mistakenly called poor because U.S. politicians and educators assume that the U.S. should always have the top scoring schools in the world - a view in which anything less than best is deemed an under-performance.

The focus on testing and scores is another concern. According to Kell and Kell (2010), there is a so-called "PISA effect" in which international testing has led to a focus on identifying and quantifying outcomes and outputs; this policy rationale which they argue is a "reductionist approach" reduces education to "attainment of narrow performance and outcome statements" (p.492). This shift in focus, they maintain, serves to suppress the more important questions about what should be taught, why it should be taught, and how it should be taught (Kell \& Kell, 2010). Likewise, scholars such as Rutkowski \& Rutkowski (2016), note that "these rankings have given rise to what effectively amounts to an international 'horse race' that identifies the educational winners and losers, with winners placed in an international spotlight and losers placed under a figurative microscope" with scholars flocking to so-called successful nations trying to better understand and replicate their educational systems' successes.

Another major concern with regards to international tests is the question of whether academic achievement can even be compared cross-nationally. Bracey (2009) is one of many scholars who believe that international comparisons are on shaky ground because international tests like TIMSS and PISA are "blunt instruments" which run the risk of making poor comparisons because of differences in each country's different student body and cultures (p.35). Turgut (2013) asks that "before interpreting test results as absolute truth and starting reform efforts based on these tests, they first should be evaluated not only for their technical but also for their cultural and societal validity and reliability" and goes on to state that in order to be applicable, they must "assess what the United States emphasizes in its educational goals and culture" (Turgut, 2013, p.70). However, while wealthier nations and wealthier students do sometimes outscore poorer ones, sub-analyses of the test data which were conditioned on students' socioeconomic status show that the effect of higher versus lower income on test scores was modest in the 1990s TIMSS tests and not a factor in the PISA 2003 data (Baker \& LeTendre, 2005). Baker \& LeTendre (2005) note that part of this effect is based on cultural differences and part comes from families investing time and money into their children's education. While one might argue that poverty and diversity are major confounding factors that 
are more relevant to the U.S. than other countries and might account for some of the achievement gap, this appears to be true mostly within countries rather than between them as TIMSS data show that "classroom diversity in student background, religious-cultural background, and so forth are not associated with cross-national achievement" (Baker \& LeTendre, 2005, p. 172).

Another very concerning aspect is the notion that testing leads to teaching to the test and that in doing so, educators will sacrifice more important aspects of education. For example, while Shanghai consistently produces the top scorers on PISA tests, Zhao (2014) notes that China may have the "best education system" because it "can produce the highest test scores", but it also has the "worst education system in the world" because those test scores are "purchased by sacrificing important aspects" such as creativity, divergent thinking, originality, and individualism.

Despite these concerns, international comparisons should not be disregarded. I think that many of the concerns are likely to be over-stated given that PISA uses open-ended questions without one right answer and because it is given in only a limited number of schools and then used as a national educational barometer but not as a high-stakes test. While any international comparison will necessarily have to deal with cross-national differences which cannot be entirely accounted for, PISA and TIMSS use rigorous methodologies and do not have external incentives to make one country look better or another worse. While all comparisons can be rightly criticized at some level, these comparative tests certainly convey enough valuable information that the arguments of critics like Kell and Kell (2010), Ravitch (2013), and Zhao (2014) do not, in my opinion, substantially invalidate their results.

\section{Educational Equity in a Diverse Society?}

In terms of educational equity, T.I.M.S.S. tells an even bleaker story for U.S. students. While one would expect disadvantaged U.S. students to perform poorly when compared to the average American student, the T.I.M.S.S. data suggest that the degree to which disadvantaged students in the U.S. fail is even more profound as "the most disadvantaged students in the United States are not just affected at one level of the school system; they fail to achieve across the span of compulsory education" (Baker \& LeTendre, 2005, p.74). Race plays an important role as well as a recent analysis of P.I.S.A. data showed White and Asian students in the United States generally perform well; the rate of low achievement for each subgroup is comparable to the rates of low achievement among the top-performing countries internationally. On the other hand, African American and Hispanic students in the U.S. have staggering rates of low achievement when compared internationally. Only Mexican students fare worse than U.S. African American students in both math and reading (Petrilli \& Scull, 2011, p.12)

P.I.S.A statistics show that $50 \%$ of African American students and $35 \%$ of Hispanic U.S. students are amongst the "lowest performers" in mathematics compared to $13 \%$ of Caucasian and $11 \%$ of U.S. Asian students (Petrilli \& Scull, 2011, p.12). In reading, $40 \%$ of African American and 25\% of U.S. Hispanic students are amongst the lowest performers compared to $11 \%$ of Caucasian and $8 \%$ of Asian students. Internationally, the percentage of U.S. Caucasian and 
Asian students who are amongst lowest performers is comparable to the percentage of students with this type of achievement in countries including Finland, Canada, and Korea, while Hispanic and African American students have similar percentages of low achieving students when compared to Israel, Mexico and Chile (Petrilli \& Scull, 2011).

Despite the fact that disparities are widespread in the United States, they are not seen to the same degree in developed nations around the world (DarlingHammond, 2010-2011, p.21). Paine and Schleicher (2011) point out that the O.E.C.D. countries that are being compared to the United States by P.I.S.A. have similar socio-economic student populations when compared to the United States. In fact, despite the fact that the U.S. has less economic inequality than 25 of the 34 nations in the P.I.S.A., only six countries showed a larger impact of socio-economic status on academic success (O.E.C.D., 2010). While these changes continue to be a major point of concern for the U.S., it should be noted that the most recent P.I.S.A test results did show that U.S. achievement gap is beginning to narrow (Barshay 2016) and is closing faster than any other nation (Richmond 2016).

\section{Resource allocation}

Among Organization for Economic Cooperation and Development (O.E.C.D.) nations, only Luxemburg spends more per child than the United States, but neither one is anywhere near the top of the P.I.S.A. rankings (Paine \& Schleicher, 2011, p.6). Furthermore, these authors also note that the U.S. is one of only four nations that spend more money on economically privileged students and less on socio-economically disadvantaged students. Comparatively, nations like Singapore and New Zealand spend less money per pupil but staff their poorest schools with more teachers per student and often with their best teachers.

\section{Teacher placement and recruitment}

A vital role for leaders in schools is "to staff the school with strong teachers and they can do this through differential retention of good teachers, through recruitment and hiring, and through providing supports for teacher improvement" (Beteille et al, 2009, p. 18-19). Only the United States has a system where teachers are allowed to teach outside of their field of expertise, something that other industrialized countries find astonishing (Tucker, 2011). In Finland, the government pays for teachers to have 2 to 3 years of rigorous graduate level preparation program to ensure that already highly qualified candidates are also well prepared for the students (Tucker, 2011; DarlingHammond, 2010).

Countries abroad have significant differences compared to the United States when it comes to respecting, valuing teachers, and advertising the importance of education through top training and being offered attractive competitive compensation (Paine \& Schleicher, 2011, p. 4). The United States spends a small amount of time training and providing real-world experiences to the novice teachers, which is likely inadequate because they are not mere "deliverers of the curriculum" but are "to become innovators and researchers in education" (Paine \& Schleicher, 2011, p.11) 


\section{International systems of education}

A number of other nations have educational systems which produce better results and more equity than does the U.S. system. Students from poorer countries like Estonia and Poland outperform U.S. students on standardized achievement tests (Finn, 1997). The U.S. is not the only country with a long history of injustice and inequality and can learn from some of the measures that countries like South Africa and Brazil are taking to try and address their problems, although certainly both countries are still struggling with this matter (Kubow \& Fossum, 2003, 107-140). However, the U.S. system is definitely unique in representing a wealthy country with high overall educational expenditures per capita (McAdams, 1993), a large achievement gap, and poor measures of academic achievement both internally and internationally. There are multiple factors that are cited as to why U.S. students do not fare well when compared with their international competitors. While issues of culture, funding, teacher training, and curriculum design are commonly cited as major barriers to the success of U.S. students, comparisons like TIMSS do not clearly demonstrate that any one factor is most important (Baker \& LeTendre, 2005).

Finland, Singapore, and South Korea are three countries that have "built strong educational systems" and have begun with "very little and purposefully built highly productive and equitable systems" all in the time span of "only two to three decades" (Darling-Hammond, 2010-2011, 21), whereas transformations in the U.S. have been tedious and unproductive. This however is a different negative effect of our current situation and "once schools become too dominated by academics, and so too competitive, many children may simply opt out of schooling, creating significant problem" (Baker \& LeTendre, 2005, p. 176). The schools in Finland, Singapore, and South Korea have made significant improvements in their educational systems during the last thirty years and some of their common strategies include "fund schools adequately and equitably, and add incentives for teaching in high-need schools", "exams having open ended questions that require deep content knowledge, critical analysis, and writing", and "teachers are well respected" and their salaries are "competitive with other careers, generally comparable to those of engineers" (Darling-Hammond, 20102011, pp. 21-2). Darling-Hammond also asserts that "similar strategies have been successfully employed at the state or provincial level in high-scoring Australia, Canada, and New Zealand, and regions such as Hong Kong and Shanghai in China" (p.22).

Some may argue that U.S. has the core subjects that students are preparing for and therefore everything else is secondary. However, in South Korea the curriculum "devotes the large majority of instructional time in every grade to a liberal arts curriculum that includes physical education, music, social studies, fine arts, science, moral education, foreign language (English), and practical arts" (Darling-Hammond, 2010-2011, p. 22). As the data presents, is that "those given the richer curriculum ultimately outperform those given the less challenging curriculum" (Darling-Hammond, 2010-2011, p.22).

Should policy makers and researchers work together to explore not only the American schools that have successfully integrated vocational and academic paths, but also the systems abroad and possibly learn from them? Bishop and 
Mane (2004) assessed the effects of offering vocational education in high schools and whether the graduation rates and future earnings were affected using data gathered from the Organization for Economic Cooperation and Development (OECD, 2010). They performed international cross-sectional data analysis and found that "nations which enroll a large proportion of students in vocational programs" had "significantly higher school attendance rates" and higher graduation rates. Countries that had more vocational education did not have a decrease in test scores amongst fifteen year-olds nor were college attendance rates reduced among students over age twenty. Students who participated in vocational programs also fared well economically. "Those who devoted onesixth of their time in high school to vocational courses earned twelve percent more salary" one year after graduation and about eight percent extra seven years later, "even compared to students who did pursue post-secondary education" (Bishop and Mane 2004). These authors therefore assert that vocational education provides substantial economic advantages to students who pursue it.

One might argue that diversity is a major confounding factor that is more relevant to the U.S. than other countries which might account for some of the achievement gap. This may be true within countries and therefore still be relevant, however, the TIMSS data do show that "school uniforms, classroom diversity in student background, religious-cultural background, and so forth are not associated with cross-national achievement" (Baker \& LeTendre, 2005, p. 172). Despite a significant amount of analysis seeking to show international achievement differences, countries internationally do not differ greatly from one another in the basics of the schooling process, especially in subjects which are easily tested like mathematics and science. While wealthier nations and wealthier students do outscore poorer ones, the effect is modest. Part of this effect is based on cultural differences and part comes from families investing in their children's education. Schools need to focus not on the success of the average or above average student, but must cater to all "for a nation to stay internationally competitive, it must not only worry about the average student and school (or the best students and schools) but also focus ever more on the weakest sections of its system" (Baker \& LeTendre, 2005, p. 173). The successful international school is the one that enables children to overcome their challenges and therefore shapes a country's society into what the society wants and this constantly varies in different countries and thus there will always be new and conflicting reforms.

\section{Japan}

One country with a history of isolationism like the U.S. which is also doing well in terms of achievement is Japan. With a highly centralized educational program, the Japanese system is intensive with a 240 day school year and "students, teachers, and parents [who] are extremely dedicated to the level necessary to achieve academic excellence" (McAdams, 1993, 225). The Japanese curriculum as a whole is nationalized, demanding, and students are uniformly held responsible for a wide variety of information (O.E.C.D., 2010). Japanese students boast a 95\% attendance rate in high school and a $97 \%$ graduation rate (Gordon, 2010). Students have a longer school day and school 
year and are expected to achieve highly both by teachers and parents (O.E.C.D., 2010). Japanese students are also regularly asked to participate in after-school tutoring sessions known as juku (Baker \& LeTendre, 2005). With all of this schooling, Japanese students were among the top five countries on the international standardized tests PISA 2006/2007 and TIMSS 2003 (Gordon, 2010). Darling-Hammond (2010) points out that Japanese schools have a much higher proportion of teachers and a lower proportion of administrators. Japanese teachers are taught to be very empathetic and the Japanese system as a whole tends to teach students to work well in groups, to care for each other, and their community (Tsuneyoshi, 2001).

In Preschool in Three Cultures Revisited, Tobin (2009) performed an indepth case study of how preschool education was implemented in classrooms in the U.S., China, and Japan. The U.S. preschools described allow teachers to "exercise their democratic societal values" (p.230) and this includes teachers teaching what they want, setting their own academic program, implementing a social and cognitive agenda, and deciding how to arrange classrooms. This method is in stark contrast to Japanese preschools in which teachers look at preschools to provide an experience where children are encouraged to figure out their own disagreements as adults wait and observe, and their intervention is kept to a minimum. The Japanese preschool system is very much rooted in Japanese culture, the preschools in Japan act as "islands of cultural continuity in a sea of social change" (Tobin, 2009, p.242). Tobin concludes that the reasoning behind Japanese values like emphasis on emotions and the development of empathy cannot be well explained, goals are not clearly discussed, even by scholars, and they are also not described in a curriculum guide or a manual. The Japanese teachers' paradigm Tobin describes is closely aligned with thinkers like Ranciere (1991) who believe that teachers should not be explicators. Indeed, Tobin (2009) describes a children's fight in which Japanese teachers act as observers, because "the main reason children in contemporary Japan need preschool is to have an opportunity to experience a level of social complexity lacking at home, adult intervention interferes with this complexity" (p.109) and Japanese teachers describe schools and their curricular approach as kyoiku (room to stretch) or dosen (lines of flow) "emphasizing that activities should be child-initiated ... and emphasize the importance of children's choice" (p.128). While the level of self-learning that can happen at a preschool is likely different than in a primary or secondary school, the Japanese preschools demonstrate that teachers should act as facilitators rather than generals and explicators, in order to promote a creative supportive learning environments.

One of the results of these Japanese approaches is that Japan has a much smaller achievement gap than other nations: only $9 \%$ of PISA scores in Japan are attributed to socioeconomic status compared to $14 \%$ globally and $17 \%$ in the U.S. (Semuels, 2017). This may also be due to other factors including the best teachers being assigned to districts which need them most, and being moved to high-need schools every three years. Even though Japan is more homogeneous, it is becoming increasingly diverse with immigrants from a number of Asian countries and initially struggled to accept this ever-growing number of foreigners (Tsuneyoshi, 2001, 124-5). However, as the government has accepted this influx of people, its education system has worked hard to "ensure equitable 
educational opportunities are available to virtually every Japanese student, regardless of the wealth of his/her parents" (McAdams, 1993, 225).

Tucker (2011) argues that in an attempt to remain competitive, the Japanese system has adapted successful aspects from the French, English, and German educational systems, as well as the Confuscian virtues of hard work, honesty, respect and loyalty. In this sense, the Japanese system attempts to create students who are balanced and not overly focused on tests. Furthermore, teaching in Japan is seen as a desirable and prestigious profession, and teachers are also among the highest paid professionals. Some Japanese leaders are concerned that their system stifles the type of creativity that creates so-called business and technological "breakthroughs"; however, they instead have continuous improvement of almost everything most of the time and this is probably better than having occasional breakthroughs (Tucker, 2011, p.98).

\section{China}

Tucker (2011) notes that in Shanghai, they employ an approach to achieving results, and implement reforms to "catch [schools] up with changes in society", which means "setting new goals and aiming at a different plane" (p.42). Focusing on eight domains of learning (which include "language and literature, mathematics, natural sciences, social sciences, technology, arts, physical education, and practicum"), rather than concentrating on standardized tests, the various parts of the system are designed to work together to aid with a fundamental understanding of each of these domains (p. 35). To accomplish this, the Chinese have invested in weaker schools, reduced disparity by providing free textbooks and exempting students from tuition, and transferring outstanding teachers and principals to schools where they were needed the most. The authors conclude that Shanghai is successful today because it aims high and is not afraid to change the status quo.

This notion of change in the Chinese schools is echoed by Tobin (2009) who examined Chinese preschools. Due to the modern Chinese understanding of entrepreneurial capitalism, the focus of early education is no longer on control or regimentation with teachers instructing and children silently obeying like it used to be. Instead, it is now on active play-based teaching and learning, creativity, working with a more children initiated curriculum, independence and promoting what China views now as ideal, the individuality of a child, even though the concept of individuality was previously feared and viewed as something that needed correction though "loving control" (Tobin, 2009, p. 226). Critics argue that the characteristics of this new path of individualism and creativity are dangerous because they are linked with "egoism and hedonism" (Tobin, 2009, p.227).

A cultural artifact that remains today that has existed since prerevolutionary periods is criticism, which is meant in Confucianism to "cultivate learning and promote social values" (Tobin, 2009, p. 68). Criticism is not only practiced during the professional development of educators, but preschool age children in China are also encouraged to actively engage in listening and offer meaningful comments about self and others as part of a critique during the content and effectiveness of play, story-telling, and other child-initiated activities. American educators, on the other hand, are surprised and concerned 
about the dangers of damaging children's self-esteem during this sort of critical feedback.

\section{Finland}

Finland, whose students achieve at the top of international tests like PISA, has invested in teacher education so that highly qualified teachers can autonomously design curricula that focus on higher-order thinking (Darling Hammond, 2010). In Finland, teaching is a profession that is respected by the general population and nation's leaders and is viewed as honorable and is among the other distinguished professions as lawyers and doctors with relative compensation offered (Paine \& Schleicher, 2011; Tucker, 2011). Teachers are also given a great degree of autonomy. To contrast, teaching in the United States is low paying, low prestige, and high stress; approximately 50 percent of teachers leave the field within their first five years of teaching (Paine \& Schleicher, 2011, p. 4). The Finns are also able to retain high quality teachers and therefore uphold their commitment to universal high academic achievement (O.E.C.D., 2010). Finnish schools provide far more social support for students as well: students can expect hot meals, psychological counseling, health and dental services at school.

In addition, the Finns have invested heavily in early childhood education requiring all elementary students to learn three languages "because nowhere else in the world do they Speak Finnish!" and are provided with free daycare in centers which are innovatively designed for the purpose of child care (Swiniarski et al., 1999, 51).

Finland has been successful in achieving increases in academic achievement despite that fact that it is becoming more diverse with an increasing immigrant population and has avoided the inequities of the achievement gap (Darling-Hammond, 2010). Even ethnic minority groups like the northern indigenous groups the Sami, Kven, and Tornedalians who were formerly "ridiculed and marginalized because of language and culture" have undergone a cultural revitalization within the schools whereby "the children's background and previous knowledge is taken as a basis for further education" and "a cooperation between the school and the home and community is created" (Huss, 2001, 154-155).

In the chapter about Finland by Schwartz and Mehta (Tucker, 2011), the authors describe a nation which collectively and apolitically decided to create a strong educational system by hiring highly knowledgeable and skilled teachers and educating all students to the same high level. When the Finns focused on global competitiveness as defined by the kinds of skills, knowledge and disposition that young people needed to possess in order to be successful (p.58), they sought to strengthen teacher quality. Not only were all teachers required to obtain a master's degree, but the authors describe how teachers in Finland function as facilitators of active creation and independent learning activities for each student and are engaged in peer collaboration and professional development that is built within a working day.

Schools in other countries do function differently and may offer important insights into the applicability of Ranciere's methods . DarlingHammond (2010) notes that in Finland "it is rare to see a teacher stand in front 
of the classroom lecturing the students.... Instead, students are likely to be conducting science investigations, measuring, building, or calculating answers to design problems" (p.170). Furthermore, students have individual learning goals and complete independent projects; this allows for more educational innovation: "the cultivation of independence and active learning allows students to develop metacognitive skills that help them tackle, and solve problems; evaluate and improve their own work; and guide their learning processes in productive ways" (Darling-Hammond, 2010, p.170). While part of the appeal of the Finnish system is that teachers are required to use "research-based, state-ofthe-art practice" (171), it is unclear if this is synonymous with functioning as an ignorant schoolmaster (p.171). While the well trained teachers likely do still impart knowledge to a certain degree, the system which is "intended to improve through continual reflection, evaluation, and problem solving" likely does a better job avoiding stultification and promoting students' educational emancipation (Darling-Hammond, 2010, p.175).

While Finland remains an exemplar nation, scholars like Rutkowski \& Rutkowski (2015) note that focusing on individual nations successes is perilous. The 2015 PISA tests showed that Finnish students saw a decline of 11 points in science, 5 points in reading and 10 points in math leading some scholars to question whether Finland is a leading educational system and why its students are not scoring as well as they had previously (Heim 2016).

\section{Singapore}

In Singapore, reform has been focused in order to "develop a creative and critical thinking culture within schools, by explicitly teaching and assessing these skills for students-and creating an inquiry culture for teachers as well" (Darling-Hammond, 2010, 182). All students have an equal opportunity to attend all schools and financial barriers are nearly eliminated. Paine and Schleicher (2011) explain that $43 \%$ of Singapore's population consists of foreign born citizens, a very diverse population. Singapore's status as the top scoring country on the 1995, 1999, 2003 TIMSS test comes despite being a multiethnic and multicultural nation (Whetstone, 2010). They even have an official policy of multiculturalism in the form of policy with English as the basic language and the ethnic languages for bilingual second languages purposes - Malay, Tamil, and Mandarin to "help both to increase employment opportunities and to reduce communication and racial barriers, thus contributing to a more harmonious and better-integrated society" (Horsky \& Chew, 2004, p. 253). Reform in this country has built a culture of inquiry and thus focused to develop creative and critical thinking skills for students (Darling-Hammond, 2010). Furthermore, "Singapore has demonstrated an unfailing commitment to equity and meritocracy", by taking steps to "reduce the achievement gap (that) has been both social and educational" (O.E.C.D., 2010, p.167). The government in Singapore aims to fix social ill because it believes that the causes of school failure lie in social situations such as single-parent families and has therefore "developed a system of local councils that identify families in need" and can provide financial and other kinds of support to struggling families (O.E.C.D., 2010).

Even though initially, vocational education in Singapore had low status and was viewed as a "dumping ground", integration of vocational education has 
been integral in this nation's success as well. Dropout rates have declined significantly due to the fact that the system does not have a one-size-fit-all philosophy of education and there are "multiple pathways for students in order to reduce wastage rates" that can either lead to college or advanced occupational and technical training in order to produce highly skilled workers that are needed for the diversely competitive economic world (Tucker, 2011, p. 117).

Stewart (2010) explains how their educational system has used the "Dream, Design, Deliver" slogan as a driving force for innovation and implementation (p.114). Focusing on holistic education, shared national goals, and collaboration amongst actors within educational and political agencies, the system in Singapore succeeds for a variety of reasons. Even vocational schools are of high quality and seen as advanced institutions that have been re-designed with the ideas of students being "hands-on, minds-on, hearts-on" (p.127) . The Singaporean system also regularly and actively researches education in Australia, Hong Kong, Sweden and Scotland which is carefully analyzed in order to adapt and implement useful strategies locally.

\section{Canada}

Mehta and Schwartz (2011), demonstrate how a country very similar to the U.S. in terms of economic and cultural diversity has succeeded using different educational policies and strategies. Common national curriculum, training and selecting the top teachers, a national reform agenda, and equalizing funding are among the top Canadian goals much like the other high-achieving nations. Canada, with a decentralized education system that is very similar to that of the United States, became one of the top performers on the 2006 PISA, therefore United States has much to learn regarding revitalizing the failing schools (Paine \& Schleicher, 2011, p.3). Three major factors cited which explain Canadian educational success are cultural factors like high levels of parental support, Canadian embrace of a welfare state and thus a sense of need to give a high quality education to all students, and policy factors which have led to a pool of highly qualified teaching candidates and funding which is equalized based on student neediness (O.E.C.D., 2010). Tucker (2011) notes that Canadian schools have improved significantly largely in part to the fact that after making their financing more equitable, they have depended on their teachers to raise the achievement of students who were previously doing least well. Furthermore, students who are not engaged by the academic curriculum have a "different menu of courses" and are able to gain valuable skills that lead to employment opportunities (Tucker, 2011, p. 157).

\section{Bringing International Successes Home}

Translating international educational successes into the American system can prove to be difficult, largely in part to cultural differences which make success possible in one place but do not exist in another (Bracey, 2009). Semuels (2017) notes that compared to nations like Japan who nationally direct more resources and better teachers to students or schools that are struggling and focus on teacher collaboration, it "could be difficult to transplant to the United States, where education has long been managed on a local level, and where talk of sharing resources more often leads to lawsuits than it does to change". 
However, Tucker (2011) argues that rather than trying to implement entire programs from abroad with all of their cultural underpinnings, the U.S. system can at least benchmark internationally by basing its educational strategies on successful strategies from abroad rather than investing in untested initiatives. Darling-Hammond (2010) argues that in order to develop children, the U.S. must change its culture to invest more in children. Specifically, she makes the case that structuring reforms to focus on learning goals, accountability systems, fair resource distribution, professional standards and supports for teachers, and re-organizing schools to promote learning will be tantamount to achieving this goal. A failure to do so, she asserts, would lead the U.S. to "devolve into a third class power because we have neglected our most important resource for creating a first-class system of education" (DarlingHammond, 2011).

\section{Discussion}

No educational system is perfect. However, given the large differences in educational outcomes presented here, it is clear that some systems do work well and are worth studying and learning from. While it may be tremendously difficult to translate successes from abroad, the hard work and research necessary may allow the U.S. system to avoid fruitless experimentation and employ strategies which are most likely to be successful.

In the international context, writers, critics and scholars struggle to define educational success and effective schools especially since most of their definitions stem from the Program for International Student Assessment (P.I.S.A.) and the Third International Mathematics and Science Study (T.I.M.S.S.) two valuable and yet flawed tests.

Even though United States has a history rich in educational experimentation and creativity, much of the United States system today preserves the pre-industrialized conveyor belt system of education where children are treated like competing products with expiration. By comparison, international countries like Canada, Finland, Singapore, and Japan have a drastically different idea and treatment for student learning and resource allocations, teacher value, placement and recruitment and overall balance and life learning all of which help their students perform at high levels.

Spring (2008) notes that global organizations and tests "exert an international force experienced at the local level", what he terms glocalizationa combination of global and local, and the result is schools "wanting to impress their national leaders, school officials hope their students do well on these tests in comparison to other countries. The consequence is a trend to uniformly national curricula" (p. 62). Crossley (2000) notes that "context does indeed matter" and that in order for international education reform to be practical, there "must be partnerships that recognize the importance of cultural differences, and the need for improved mediation between the global and the local" (p. 325).

With the increasing specter of globalization, students in the United States can no longer rely on their country's economic dominance to provide them wellpaying jobs. Competition that exists not only within our diverse population but also internationally with well-educated students abroad will make the global marketplace increasingly competitive. In order to ensure the U.S. does not fall 
far behind, leaders will need to learn from some of the strategies that make international students successful and bring them to our education system.

The challenge still remains within the international learning process of how to successfully and effectively implement foreign educational agendas within our American system of education. This is particularly daunting given not only the need to raise test scores but also to promote equality for students of all heritages and economic backgrounds, to recruit highly qualified teachers, and to increase the value of the teaching profession in general.

Not all educational policies work universally. While implementing successful international strategies sounds appealing, where and how this could or should be done is a much harder idea to describe. We need to better understand what types of international strategies American schools are likely to attempt to translate from abroad and which are likely to translate well. Specific types of barriers may prevent the use of certain international strategies in at least some U.S. localities. Whether these barriers be attitudes, resources, or funding and structural issues, research investigating which successful strategies are mostly likely to be applicable and successful after being brought from abroad would make international comparative studies like those reviewed here even more productive.

\section{References}

Baker K. (2007). Are International Tests Worth Anything? Phi Delta Kappan, 89(2), $101-$ 104. https://doi.org/10.1177/003172170708900205

Baker P. \& Letendre K. (2005) National Differences, Global Similarities: World Culture and the Future of Schooling. Stanford, California: Stanford University Press

Berliner, D.C. \& Biddle, B.J. (1996). The manustructured crisis: Myth, fraud, and the attack on public schools. New York: Perseus. https:// doi.org/10.1177/009430610603500361

Barshay, J. (2016). U.S. now ranks near the bottom among 35 industrialized nations in math. The Hechinger Report. Retrieved from: http://hechingerreport.org/u-snow-ranks-near-bottom-among-35-industrialized-nations-math

Bishop, J., \& Mane, F. (2004). The impacts of career-technical education on high school labor market success. Economics of Education Review. 23, 381-402. https:// doi.org/10.1016/j.econedurev.2004.04.001

Boe, E. \& Shin, S. (2005). Is the United States Really Losing the International Horse Race in Academic Achievement? Phi Delta Kappan, 86(9), 88-695. Bracey, G. (2009). Big tests: What ends do they serve? Educational Leadership, 67 (3), 32 - 37. https://doi.org/10.1177/003172170508600913

Cavanagh, S. (2012). Complex Policy Options Abound Amid International Comparisons. Education Week, 31(16), 6-10.

Darling-Hammond, L. (2010-2011). Soaring Systems: High Flyers All Have Equitable Funding, Shared Curriculum, and Quality Teaching. American Educator, v34, n4, pp. 20-23, 53.

Darling-Hammond, L. (2010). The flat world and education: How America's commitment to equity will determine our future. NY: Teachers College Press

Darling-Hammond, L. (2011). The Global Appreciation of Teachers. Message posted to http://www.forumforeducation.org/blog/global-appreciation-teachers

Heim, J. (2016). Finland's schools were once the envy of the world. Now, they're slipping. Washington Post (December 8, 2016). Retrieved from: https://www.washingtonpost.com/local/education/finlands-schools-were- 
once-the-envy-of-the-world-now-theyre-slipping/2016/12/08/dcfd0f56-bd60-

11e6-91ee-1adddfe36cbe_story.html?utm_term=.1e1a700d6aec

Hofman, W., Hofman, R., \& Gray, J. (2010) Institutional contexts and international performances in schooling: Comparing patterns and trends over time in international surveys European Journal of Education, 45 (1), 153 -173. https://doi.org/10.1111/j.1465-3435.2009.01420.x

Horsky, B.. \& Chew, C. (2004). Singapore: Schools in the Service of Society. In Rotberg, I. (Ed.), Balancing Change and Tradition in Global Education Reform (pp. 245260). Lynham, Maryland: Scarecrow Education

Huss, L. (2001). Language, Culture, and Identity in the Schools of Northern Scandinavia. In Grant, C.A. \& Lei, J.L. (Eds.), Global Constructions of Multicultural Education: Theories and Realities (pp. 135-158). New Jersey: Lawrence Erlbaum Associates

Kell, M. \& Kell, P. (2010). International Testing: Measuring Global Standards or Reinforcing Inequalities. International Journal of Learning, 17(9), 485-501.

Kubow, P. \& Fossum P. (2003). Comparative Education: Exploring Issues in International Context. Upper Saddle River, NJ: Merrill Prentice Hall.

McAdams, R. (1993). Lessons from Abroad: How Other Countries Educate Their Children. Lancaster, PA: Technomic Publishing Co. https:// doi.org/10.1086/447294

Organization for Economic Co-operation and Development. (2007). Education at a Glance 2007: Highlights. Retrieved from www.oecd.org/dataoecd/4/55/39313286.pdf https://doi.org/10.1787/eag2007-en

Organization for Economic Co-operation and Development (2010), Strong Performers and Successful Reformers in Education: Lessons from PISA for the United States http://dx.doi.org/10.1787/9789264096660-en

Organization for Economic Co-operation and Development. (2011). Lessons from PISA for the United States: Strong Performers and Successful Reformers in Education. Retrieved from http://dx.doi.org/10.1787/9789264096660-en https://doi.org/10.1787/9789264096660-12-en

Organization for Economic Co-operation and Development. (2016). PISA 2015 Results in Brief. Retrieved from https://www.oecd.org/pisa/pisa-2015-results-infocus.pdf. https://doi.org/10.1787/bc6256e2-en Paine, S. \& Schleicher, A. (2011). What the U.S. can learn from the world's most successful education reform efforts. New York, NY: McGraw-Hill Research Foundation.

Partnership for 21st Century Skills. (2009). 21st Century Skills, Education \& Competitiveness: A resource and policy guide. Tucson, AZ

Payne M. C. (2010). So Much Reform So Little Change: The Persistence of Failure in Urban Schools. Cambridge, MA: Harvard Education Press. https:// doi.org/10.1007/s10833-009-9129-7

Petrilli, M. \& Skull, J. (2011). American Achievement in International Perspective. Washington, D.C.: Fordham Institute Press

Ranciere, J. (1991). The Ignorant Schoolmaster: Five Lessons in Intellectual Emancipation, K. Ross (trans.). Stanford, CA: Stanford University Press

Ravich, D. (2013) Reign of Error: The Hoax of the Privatization Movement and the Danger to America's Public Schools. New York: Vintage Books https:// doi.org/10.1177/0160597615588787

Richmond, E (2016). How Do American Students Compare to Their International Peers? The Atlantic (December 17). Retrieved from: https://www.theatlantic.com/education/archive/2016/12/how-do-americanstudents-compare-to-their-international-peers/509834/ 
Rutkowski, L. and Rutkowski, D. (2016). A Call for a More Measured Approach to Reporting and Interpreting PISA Results. Educational Researcher, Vol. 45 No. 4, pp. 252-257. http://journals.sagepub.com/doi/pdf/10.3102/0013189X16649961. https:// doi.org/10.3102/0013189x16649961

Schleicher, A. (2009). Seeing the United States Education System through the Prism of International Comparisons. Middle School Journal, 40(5), 11-17. https:// doi.org/10.1080/00940771.2009.11461685

Schwartz, R. \& Mehta, J. (2011). Finland: Superb Teachers - How to Get Them, How to Use Them: Surpassing Shanghai: An Agenda for American Education Built on the World's Leading Systems (M. Tucker, editor), Harvard Education Press

Semuels, A (2017). Japan Might Be What Equality in Education Looks Like. The Atlantic (August 2, 2017). Retrieved from: https://www.theatlantic.com/business/archive/2017/08/japan-equaleducation-school-cost/535611/

Swiniarski, L.A, Breitborde, M., \& Murphy J. (1999). Educating the Global Village: Including the Young Child in the World. Upper Saddle River, NJ: Prentice Hall, Inc.

TIMSS \& PIRLS International Study Center (2013). TIMSS 2015 Assessment Frameworks. Lynch School of Education, Boston College.

Tobin, J., Hsueh, Y., \& Karasawa, M. (2009). Preschool in Three Cultures Revisited: China, Japan, and the United States. Chicago: University of Chicago Press. https://doi.org/10.7208/chicago/9780226805054.001.0001

Tsuneyoshi, R. (2001). The Japanese Model of Schooling: Comparisons with the United States. New York: Routledge Falmer. https://doi.org/10.4324/9780203357668

Tucker, Marc. (Ed.). (2011). Surpassing Shanghai: An Agenda for American Education Built on the World's Leading Systems. Cambridge, MA: Harvard Education Press.

Turgut, G. (2013). International Tests and the U.S. Educational Reforms: Can Success Be Replicated? The Clearing House: A Journal of Educational Strategies, 86(2), 6473. https:// doi.org/10.1080/00098655.2012.748640

Whetstone, D. (2010). New math: How U.S. schools can realize Singapore's success in Mathematics achievement, Crossings www.csutan.edu/honors/documents/journals/crossings/Whetstone.pdf

Zhao, Y. (2007). Education in the flat world: Implications of globalization on education, Edge Magazine (Phi Delta Kappa International), 2(4), 1-19.

Zhao, Y. (2014). Who's Afraid of the Big Bad Dragon?: Why China Has the Best (and Worst) Education System in the World. San Francisco: Jossey-Bass. 